\title{
Folklore and Northeast Indian History
}

\author{
Meeta Deka \\ Department of History, Gauhati University, Gauhati, India. \\ Email: meetadeka@gmail.com

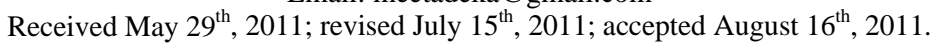

\begin{abstract}
The article intends to highlight folklore as an alternative source for the writing of history, particularly of the northeastern region of India, which is inhabited by numerous tribal communities, and where there is a dearth of written documents, archaeological and other evidences. Folklore as a source is important to explain and understand societies in the context of preserving cultural diversity and protecting minority cultures, especially those of indigenous peoples and marginalized social groups. With the increased growth of several ethnic identity crises in the region in recent times, the roots for their respective indigenous history are often traced to folklore.
\end{abstract}

Keywords: Cultural Heritage, Alternative Source, Traditional Knowledge

\section{Introduction}

Folklore is an important source for the writing of history, particularly of the northeastern region of India, which comprises of seven states namely Assam, Arunachal Pradesh, Meghalaya, Mizoram, Nagaland, Manipur, and Tripura and inhabited by numerous tribal communities such as Adi, Apatani, Angami, Ao, Rengma, Nyishi, Garo, Khasi, Synteng, Mizo, Kuki, Bodo, Missing, Dimasa, Nepalese, Riang, Trippera and Tripuri, where there has been a dearth of written documents, archaeological and other evidences. As an alternative source, folklore is significant to explain and understand societies in the context of preserving cultural diversity and protecting minority cultures, especially those of indigenous peoples and marginalized social groups like the peasantry, labour, ethnic tribes, and women. Folklore as an important element of the cultural heritage of every tribe, andnation, becomes important to history as well. Folklore of a group reinforces its sense of ethnic and social identity. It is a living and still developing tradition, rather than just a memory of the past, particularly with the growth of ethnic crises in recent times. It is through such an understanding that folklore is considered as an important source for history. The attainment of such importance also demands the need for intellectual property protection of expressions of folklore that is made necessary vis a vismodern information technologies.

Although WJ Thoms coined the term "folklore" as early as 1846, its implications changed over time to become more comprehensive. The amorphous term "folklore" tends to emphasize its diverse nature, consisting of, for example, the "traditional customs, tales, sayings, or art forms preserved among a people.” (Webster, 1984). In this sense, the term applies not only to ideas, or words, but also to physical objects. Archer Taylor (Kuruk, 1999: Introduction) explains its multi-faceted implications in very clear terms:

The folklore of physical objects includes the shapes and uses of tools, costumes, and the forms of villages and houses. The folklore of gestures and games occupies a positioned intermediate between the folklore of physical objects and the folklore of ideas. Typical ideas transmitted as folklore are manifested in the customs associated with birth, marriage, and death, with the lesser events of life, with remedies for illnesses and wounds, with agriculture, the trades, and the professions, and with religious life. ... Verbal folklore includes. tales of various kinds (marchen, jests, legends, cumulative tales, exempla, fables, etiological tales), ballads, lyric folk song, Children's songs, charms, proverbs and riddles. (Taylor, Definitions)

Examples of folklore provided in the statutes include poetry, riddles, songs, instrumental music, dances, and plays, productions of art in drawings, paintings, carvings, sculptures, pottery, terra cotta, mosaic, woodwork, metalwork, jewelry, handicrafts, costumes, and indigenous textiles. However, traditional knowledge based on plant varieties grown by farmers, and plant extracts developed by local medicine men, also qualify as works of folklore to the extent that "these techniques embody scientific techniques passed down through generations in the community. The knowledge they embody is priceless and, once lost, cannot be recovered". Widespread exploitation of such types of traditional knowledge justify their inclusion in any protective legal regime. Apart from its entertainment value, folk music serves as a means of recording history by preserving information about important past events. Music also plays vital roles in rituals and festivities, as a palliative in healing, as part of war preparation, and as a means for criticizing or checking governmental abuses. Dance and drama are also linked to rituals and religious festivities, while designs on fabrics and art may depict religious, social or cultural concepts. In popular usage, the term folklore is sometimes restricted to oral literature tradition. However, in modern usage, folklore is an academic discipline, the subject matter of which (also called folklore) comprises the sum-total of traditionally derived or orally or imitatively transmitted literature, material culture and custom of sub-cultures within predominantly literate and technologically advanced societies (Webster, 1984). This new definition emerged, rather developed, through the ages to include its importance for the reconstruction of the history of "the people".

Collection of Indian folklore, as represented by the Panchatantraor Indian fables, the Jatakas or stories related to the life of Gautama Buddha, to name a few, can be traced to very early times. In the west, the collection of folklore began late. Inspired by the Grimm brothers, whose first collection of fairy tales appeared in 1812, scholars all over Europe began recording and publishing oral literature. At first they concentrated exclusively on rural uneducated peasants and a few other groups, like the gypsies for example, which arerelatively untouched by modern ways. Their aim was to trace preserved archaic customs and beliefs to their remote origins in order to 
trace the mental history of mankind. In Germany, Jacob Grimm used folklore to illuminate Germanic religion of the Dark Ages. In Britain,

Sir Edward Tylor, Andrew Lang and others combined data from anthropology and folklore to "reconstruct" the beliefs and rituals of pre-historic man. Sir James Frazer's The Golden Bough (1890) is a good example of such an effort. Soon large collections of material were amassed in the course of these efforts and many archives and museums were founded. Folklore soon acquired nationalistic overtones as it reinforced the ethnic identity of a social group, it figured prominently in many struggles for political independence and national unity (TNEB).

\section{Importance of Folklore as a Source for History-Writing}

Hence as the scholarship of folklore developed, with new aims, scope andmethodologies, its importance as a source of history also grew. In fact the first formal association between history and folklore is apparent in the title of a book on folklore written by George Lawrence Gomme: Folklore as a Historical Science published in 1908. BirenDutta, a renowned folklorist of the region, states that although folklore is no longer accepted as a historical science, he identifies its association with history through the use of the term "historical" to two schools of folkloristics: (Dutta, 2002: p. 25).

The first, the Historical-Geographical School was at one time the most influential theoretical and methodological tool that was applied to folklore data by scholars in Europe and America”. An important advance was the classification of material for comparative analysis. Standards of identification were devised, notably for ballads by FJ Child and for the plots and component motifs of folktales and myths by Antti Aarne and Stith Thompson. Using these, Finnish scholars, led by Karle Krohn, developed the "historical-geographical" method of research, in which every known variant of a particular tale, ballad, riddle or other item were classified as to place and date of collection in order to study distribution patterns and reconstruct "original" forms. In other words it is based on the diffusionist theory that like cultural traits, folklore items initially originate in a particular place and are transmitted to other places through the process of diffusion. This method, more statistical than speculative than that of the anthropological folklorists, dominated the field throughout the first half of the 20thC. The second was the Historical-Reconstructional School which tried to "recapture vanished historical periods for which other evidence is scanty" (Dorson, 2002: pp. 12-13). Dutta states that both the schools are related to the ideas of evolutionism and devolutionism* (Dutta, 2002, p. 24). Both the schools were attempts at the reconstruction of prehistory and history.

From the year 1930 onwards immense developments and changes were taking place both in Folklore Studies as well as in History. In folklore studies, ideas related to evolution and devolution were ejected in favor of a more scientific approach. After the World War II new trends emerged, particularly in the United States. Interest was no longer confined to rural commu-

\footnotetext{
*The evolutionary theory represented a framework of a unilinear cultural evolutionary sequence moving from savagery through barbarism to civilization. The peasantry represented the 'barbarian' or 'uncivilized 'section within a civilization, the 'non-progressive class in a progressive people' and the 'non-literate in a literate society'. Exponents of this theory are Max Muller, the German Orientalist, EB Tylor, the British Anthropologist and Lewis Henry Morgan, the American Anthropologist. 'Devolutionism' implied that as society progresses in an evolutionary way towards more advanced stages of civilization, folklore devolves or decays at an equal rate.
}

nities, since it was recognized that cities too contained definable groups whose characteristic arts, customs and values marked their identity. Although some scholars continued to regard folklore as belonging solely to the working classes, in other circles the concept lost its restrictions of class and even of educational level. In fact, any group that expressed its inner cohesion by maintaining shared traditions qualified as a "folk", whether the linking factor be occupation, language, place of residence, age, religion or ethnic origin. Emphasis also shifted from the past to the present, from the search for origins to the investigation of present meaning and function. Change and adaptation within tradition were no longer necessarily regarded as corruptive (TNEB).

Dutta has identified the various stages of development of modern folkloristics in India and that the introduction of Departments of Folklore in universities is a post-independence phenomenon. One of the earliest established departments in India was that of Gauhati University, by Birinchi Kumar Barua in 1955. He stated that after the 1980s folkloristics have become much more extensive with new perspectives and specialization (Dutta, 2002, pp. 18-20). Richard Dorson has identified four broad sectors in folkloristics, viz., Oral literature, Material Culture, Social Folk Custom and Performing Folk Arts (Handoo, 1985: pp. 7-14), which have great significance for the reconstruction of history.

In history also, great changes and new trends made headway. It was in the 1930s that the term "history from below" was coined by the French historian, Georges Lefebvre. However it gained importance only in the 1960s through the writings of British Marxist historians like EP Thompson. "History from below" also had exponents like Emmanuel Le Roy Ladurie of the Annales School through what is called "cultural history" or the "history of the mentalites". "History from below" is an attempt to understand "real" people, to expand the frontiers of social history in accordance with what Marx called the need to understand the "masses". It promoted the evaluation of the lives and thoughts of pre-modern peasants, the development of the working class, the activities and actions of women and men, which were regarded as unimportant by scholars.

Thus the focus of history has moved away from the political history of kings, rulers and white-collared officials to the writing of "New" social, economic and cultural histories wherein the ordinary women is put back into historical narratives, and wherein historians have turned their investigations to the development of group identities, particularly workers, peasants, racial and ethnic types. The emphasis of gender in history too began particularly since the 1960s, when the feminist movement and feminist thought made an extraordinary impact in the social sciences and humanities; Gender in history has since then been the central concern and focus of recent research.

Most written documents were silent on such aspects and hence such a shift of focus perforce has led to the necessity of using folklore as an important alternative to fill up the so called gaps or blanks of history. Thus while history itself has expanded its horizon of study, it has also diversified its sources by moving away from conventional sources to unconventional ones. The importance of folklore as a source for the writing of history is to be found in the insight of a particular story, song, drama or custom which may reflect the social and economic conditions of that particular time in which it was formulated. Hence each phenomenon constitutes more than a mere instance to be recorded and compared with others of the same category; it should be regarded and understood within its total context, as arising from the interaction between individuals and their social 
groups, and between man and environment as well.

However, there are pertinent dangers in the usage of folklore as a source of history as well. Herein lies the responsibility of the historian. JB Bhattacharjee summarizes its place in history thus: “...historians will not use folklore as a source without examining the acceptability of the information according to the standard methods of verification of sources and elimination of the possible impact of ignorance or motive or compulsion in each narration. The use of folklore material is recommended when the standard sources are either scanty or absent, or the folklore is able to provide additional information or to supple- ment the conventional sources" (Bhattacharjee, 2003: p. 29). In the application of folklore contents and implications to history, of discerning the "historical sense" in folklore, the historian will have to be aware of the thin line that exists between history and myth, tradition and folk tales, that between oral history and oral tradition, as also between history, oral history and oral tradition. This calls for a combination of methodologies of history and folklore. In this, the works of Jan Vansina (Oral Tradition as History” (1985), Richard Dorson (Folklore and Folklife: An Introduction (1972)) and David Bynum (Oral Evidence and the Historian: Problems and Methods (1973), would be extremely helpful in providing such methodologies. (Dutta, 2002: pp. 67-69).

While the importance of folklore as a source increased, the question of protection of traditional knowledge and folklore became increasingly important with the emergence of a "global information society" in recent years, characterized by the rise of modern information technology. Traditional knowledge and folklore are thus receiving increased attention in numerous policy fora and debates, ranging from food and agriculture, the environment, health, human rights, and cultural policy, to trade and economic development. The concept of "traditional knowledge" emerged independently in several contexts such as environment conservation, agriculture and food security, traditional medicine as a source of primary health care, indigenous knowledge, in the context of preserving cultural diversity and protecting minority cultures, especially those of indigenous peoples. It is the last mentioned context with which the writing of history is concerned.

The need for intellectual property protection of expressions of folklore emerged in developing countries like India. Although improper exploitation of folklore was present in the past, the spectacular development of technology, the newer ways of using both literary and artistic works and expressions of folklore, like audiovisual productions, phonograms, their mass reproduction, broadcasting, cable distribution, and so on, have multiplied abuses. Folklore is commercialized without due respect for the cultural and economic interests of the communities in which it originates. And, in order to better adapt it to the needs of the market, it is often distorted. At the same time, the communities who have developed and maintained it, are deprived of any profit derived from such ventures. In 1982 a joint venture of WIPO and UNESCO undertook activities to address the intellectual property aspects of traditional knowledge and folklore and it resulted in the "Model Provisions for National Laws on the Protection of Expressions of Folklore Against Illicit Exploitation and other Prejudicial Actions" (WIPO, pp. 56-57). National Laws were framed by developing countries like Africa Sri Lanka (1979); Indonesia (1987); China (1990) etc., to regulate the use of folklore creations and to provide protection in the framework of their copyright laws .Some of these national laws however, do not provide a substantive definition; at most, they mention that what is involved is common national heritage. However, the definitions in the laws of Benin and Rwanda are much broader and also extend to other aspects of folklore, as for example, to scientific and technological "folklore" such as, acquired theoretical and practical knowledge in the fields of natural science, physics, mathematics and astronomy; the "know-how" of producing medicines, textiles, metallurgical and other products; agricultural techniques.

The protection of such elements of folklore is obviously alien to the purposes and structure of copyright. It follows from the fact that folklore is part of traditional heritage that it would not be appropriate to leave its protection to some individual "owners of rights." In principle, it could be a solution to entrust the communities concerned with exercising - through their representatives - the rights granted for the protection of the folklore developed by them. However, all the national laws providing for "copyright" protection of folklore rather authorize various national bodies to exercise such rights. In certain countries, those bodies are the competent ministries or similar national authorities, while in some other countries, they are the national (state) bureaus for the protection of authors' rights.

As the laws varied from country to country, the 1967 Stockholm Diplomatic Conference for revision of the Berne Convention made an attempt to introduce copyright protection for folklore also at the international level. However, copyright law may not be the right, or certainly the only, means for protecting expressions of folklore. This is because, whereas an expression of folklore is the result of an impersonal, continuous and slow process of creative activity exercised in a given community by consecutive imitation, works protected by copyright must, traditionally, bear a mark of individual originality. Traditional creations of a community, such as the so-called folk tales, folk songs, folk music, folk dances, folk designs or patterns, may often not fit into the notion of literary and artistic works. Copyright is author-centric and, in the case of folklore, an author-at least in the way in which the notion of "author" is conceived in the field of copyright-is absent (WIPO, pp. 58-64).

The Model Provisions were regarded as the first step in establishing a sui generis system of intellectual-property-type protection for expressions of folklore. They were designed for a proper guidance for national legislation so as to maintain a proper balance between protection against abuses of expressions of folklore, on the one hand, and of the freedom and encouragement of further development and dissemination of folklore, on the other. The Model Provisions did not necessarily have to form a separate law; they might constitute, for example, a chapter of an intellectual property code or of a law dealing with all aspects of the preservation and promotion of national folklore. The Model Provisions defines the term "expressions of folklore" as productions consisting of characteristic elements of the traditional artistic heritage developed and maintained by a community in the country or by individuals reflecting the traditional artistic works (WIPO, pp. 58-64).

Extending statutory rights and remedies to folklore would significantly improve the protection available under customary law. It would mean that rights to folkloric works could be enforced within national boundaries instead of under the limited jurisdictional confines of the local community. The national court system would also complement the authority of elders and other group leaders and strengthen prohibitions and conventions regarding the use of folklore. Traditional communities would have greater control over the use of their works. Like any subject of copyright, (scientific, literary and artistic works), folklore is the result of a creative process. Folklore takes the same form as any subject of copyright, that is, the form of a work. Strictly speaking, folk songs can be regarded as a varia- 
tion on the kind of song that is protected by copyright, while folk art productions can be assimilated to decorative art, etc. So with regard to their form of expression, works of folklore are comparable to the works protected by copyright. With respect to their content, of course, folk productions do differ from authors' works, but the distinction has no bearing on the provision of legal protection. Advocates for the expansion of intellectual property law to folklore also believe that clothing designs, sophisticated marks on agricultural implements, and carvings could be protected as trademarks while the technology processes in cloth-weaving, metal-working, constructing musical instruments, and the practice of herbal medicine could be patented. As a practical matter, however, it may be difficult to protect these rights under the general provisions of statutory law. There are inherent difficulties in fitting folklore into certain accepted notions of intellectual property relating to ownership, originality, duration, fixation, inventiveness and uniqueness (Kuruk, 1999: pp. 841-848).

It is difficult to classify indigenous knowledge innovations and practices into categories of intellectual property developed for use by commercial firms in an industrial and secular context because different concepts of ownership rights apply in traditional schemes, and folklore may not fall within the purview of intellectual property law. In traditional societies, ownership refers to the rights of all members of the community in subject matter originally acquired by ancestors which cannot be transferred unilaterally by any member of the group, including the head leader. For example, there may be a problem identifying an individual who could claim authorship given the passage of folklore through generations of people in the community. It is obvious that while an individual may have indeed created a particular work of folklore, it would eventually have been acquired and used by the society at large and gradually, with the passage of time, have lost its individualistic traits. It would be difficult to establish a framework for determining an appropriate protection period because the slow and evolving nature of folklore makes it impossible to determine precisely when a work of folklore was first created. Hence significant problems with protecting folklore under customary law, national legislation, regional and international laws are discerned. Scholars urge the recognition of moral rights in folklore as the solution to problems of distortion, misrepresentation, and authenticity that frequently accompany the unauthorized use of folklore. The argument for adopting a separate instrument for folklore rests on the fact that folklore is sui generis; despite similarities with intellectual property rights, folklore is created, owned and utilized differently (Kuruk, 1999).

\section{Conclusion}

The very cultural heritage that gives indigenous peoples their identity, now far more than in the past, is under threat of extinction. This is particularly true of Northeast India, which is inhabited by over 200 of the 635 tribal groups in the country, and what is more striking is the fact that this region, plains and hills people included, geographically secluded as it is from the mainland shares greater affinity, besides the geographical, in terms of race, culture, and tradition to its eastern neighbours, viz. China, Tibet and Myanmar than with the mainland. Identity crises have grown exponentially in the last the six decades and more in post-Independence India , allowing a flourish of cultural diversity in the region as elsewhere, adding vibrancy to national identity on one hand, while the ever-widening contours of the economic world under the process of globalization, taking the shape of the Look-East Policy and other economic developments in Northeast India, have converted this region into one of South Asia's hottest trouble spots, steeped in insurgency and secessionist movements. Ethnic identity crises have perforce drawn the attention of the various tribes to look for roots and invent a history, wherein folklore plays a remarkable role.

Hence if folklore cannot be brought under modern intellecttual property laws, then it is imperative to consider new legal protection to the traditional community's fundamental right to protect its heritage from undue exploitation. What is needed then, as suggested by Paul Kuruk, is the creation of new and indigenous agencies that would improve the existing framework of protection and regulate the use of folklore within the parameters of the state government. This would guarantee the right of the various ethnic groups and national communities to their own folklore and set up appropriate organizations such as Arts Councils, which would be open to various interest groups. As regards its importance as an alternative source to fill up gaps in history, it may be stated that the historian must first of all be aware of the basic difference between history and folklore, myths and legends; second, that the historian be trained in the finer details of methodology of both history and folklore as well, so as to generate a holistic and a meaningful reconstructtion of the past, corroborated by other evidences.

\section{References}

Webster's Ninth New Collegiate Dictionary, 1984.

Dutta, B. (2002). Folklore and historiography. Chennai: National Folklore Support Centre.

Dorson, R. M. (1972). Folklore and folklife: An introduction. In Dutta, op.cit.

The New Encyclopedia Britannica

Handoo, J. (1985). Folklore and folklife: An introduction. In S. Sen, (Ed.), Folklore in North East India. New Delhi: Omsons.

Bhattacharjee, J. B. (2003). Supplementing archival materials: Search for alternatives. In Insight: A collection of articles. Department of History. Gauhati University.

WIPO (2004) Intellectual property handbook: Policy law and use. WIPO Publication No. 489(E).

Kuruk, P. (1999). Protecting folklore under modern intellectual property regimes: A reappraisal of the tensions between individual and communal rights in Africa and the United States. URL (last checked 12 August 2009).

http://www.wcl.american.edu/journal/lawrev/48/kuruk.pdf?rd=1 